\title{
EAl Endorsed Transactions

\section{Exploring the outdoor performance of a LiDAR-based ground plane checking system for the visually impaired}

\author{
A.B.C. Chai ${ }^{1, *}$ and B.T. Lau $^{2}$ \\ ${ }^{1}$ Swinburne University of Technology Sarawak, Malaysia
}

\begin{abstract}
INTRODUCTION: Individuals with visual impairments face a variety of challenges in their daily lives, from daily activities to physical world navigation. One of the biggest challenges is the ability to travel around safely and independently. This challenge is complicated and stressed to the visually impaired as the inability to perform obstacles or ground plane checking will result in severe injury or even death.

OBJECTIVES: This work aims to prove the outdoor performance of the developed solution in detecting and recognising the frontal ground plane conditions.

METHODS: The proposed model uses a LiDAR module as a distance-measuring tool to perform ground plane checking.

RESULTS: In the selected outdoor path-based scenarios, the ground plane checking system succeeded in achieving an overall recognition rate of $93.10 \%$, with an overall false positive rate of $2.72 \%$ and average false negative rate of $4.25 \%$.

CONCLUSION: Overall, the findings showed the ability of the proposed model to provide effective frontal ground plane checking for the visually impaired.
\end{abstract}

Keywords: ground plane checking, LiDAR, sensor, path-based, ground plane conditions, visually impaired.

Received on 14 April 2020, accepted on 21 June 2020, published on 22 June 2020

Copyright (9) 2020 A.B.C. Chai et al., licensed to EAI. This is an open access article distributed under the terms of the Creative Commons Attribution licence (http://creativecommons.org/licenses/by/3.0/), which permits unlimited use, distribution and reproduction in any medium so long as the original work is properly cited.

doi: 10.4108/eai.13-7-2018.165498

"Corresponding author. Email:achun@swinburne.edu.my

\section{Introduction}

Visually impairments vary from complete blindness to severe sight loss that cannot be corrected or treated with corrective lenses or surgical procedures [1]. Individuals with vision impairments confront an assortment of difficulties in their everyday lives, from daily activities to physical world navigation [2]. One of the challenges in physical world navigation is the ability to travel around safely and independently. The issues associated with the navigation of people with visual impairment are the obstacles and ground plane conditions. The ground plane scenarios include the staircases, potholes, pits, ramps, drains, ditches, rough ground or loose surfaces.

[3] reviewed 31 selected studies and reported that people with visual impairment are 1.7 times more likely to have a drop and 1.9 times more likely to have multiple falls in everyday living activities as compared against the normally sighted persons. Moreover, the chances of getting a hip fracture are between 1.3 times and 1.9 times more prominent for those with visual impairment.

Staircases are one of the most common artificial structures within the day by day environment as it plays a vital part and gives multilevel reaching possibilities [4]. In any case, staircases are also one of the most dangerous obstacles to people with visual impairment. Descending staircases are the most dangerous hazards for visually impaired who utilise rollator or wheelchair [5]. In 2016, Stacey reported a tragedy in which a blind, wheelchairbound teenager suffered from a broken neck and passed away after falling from the stairs [6]. Through this tragic incident, it is clear that the staircases are a serious hazard 
that requires high attention, especially for the visually impaired.

Rojin, a 27-year-old teenager, expressed that the most unsafe scenario is the uncovered drains/ditches when they go out of their house [7]. The drains are very common which often exists between the streets and pavements. Besides that, Rojin shared a few experiences where one of her friends fell into a pit dug by the construction worker and the friend's jaw was shattered. Another accident occurred when Rojin was on the way to the class with her friend. All of a sudden, the friend went missing as she fell into a deep ditch and was in pain. Rojin stated that they feel stressed to go out as they always come back with a bruise on the body. From Rojin's sharing, it is evident that the ground plane condition is dangerous and important concerns for improving the mobility of visually impaired people.

Another often occurring significant incident is the fall of visually impaired people into the train platform. [8] reported a visually impaired man fell onto the train platform on 6 April 2017 and fractured his leg. Fortunately, the man was spared by two individuals who risked their lives as the incident occurred only a minute before the train arrived. In addition, Aoki reported the total number for train platform falls in Tokyo had increased to 3673 in 2014 [9]. This issue could be solved if a safety barrier is built but the problem is the massive construction expenses. So, in case the visually impaired have a device

Additionally, uncovered manholes and drains in most of the streets in Malaysia towns are virtual death traps. In January 2016, a 15-year-old student fell into an uncovered manhole and sustained serious kidney injuries [10]. The injured caused lot of internal bleeding and the teen had to get the damaged kidney removed to save his life.

So, if the visually impaired persons have a device that helped detect the area in front of them, then the likelihood of falling accidents will be significantly reduced. As to date, there are research works on technology to assist visually impaired people with ground plane checking. However, most of the existing solutions were limited to a single ground plane condition and some of them were not tested in real time outdoor environments (Table 1).

Table 1. Electronic-based Ground Plane Conditions Checking

\begin{tabular}{|c|c|c|c|}
\hline System Name & Sensing & Coverage & Limitations \\
\hline $\begin{array}{l}\text { Electronic Cane } \\
\text { [11] }\end{array}$ & $\begin{array}{l}\text { Ultrasonic } \\
\text { Sensors } \\
\text { Monocular } \\
\text { Camera }\end{array}$ & Staircases & $\begin{array}{l}\text { - Only tested with two raw data sets } \\
\text { - Good performance for staircases } \\
\text { detection only } \\
\text { - Stopped at conceptual research } \\
\text { stage }\end{array}$ \\
\hline $\begin{array}{l}\text { Step Detection } \\
\text { System [12] }\end{array}$ & $\begin{array}{l}\text { Small Laser } \\
\text { Range Sensor }\end{array}$ & $\begin{array}{l}\text { Indoor } \\
\text { steps }\end{array}$ & $\begin{array}{l}\text { - Heavy weight with sensor unit of } \\
0.5 \mathrm{~kg} \text { and a backpack of } 3.4 \mathrm{~kg} \\
\text { - Power supply and usable hours are } \\
\text { not indicated } \\
\text { - Stopped at conceptual research } \\
\text { stage }\end{array}$ \\
\hline $\begin{array}{l}\text { Smart White } \\
\text { Cane [13] }\end{array}$ & $\begin{array}{l}\text { Ultrasonic } \\
\text { Sensors }\end{array}$ & $\begin{array}{l}\text { Indoor and } \\
\text { outdoor } \\
\text { white cane }\end{array}$ & $\begin{array}{l}\text { - Experimental results were not } \\
\text { presented } \\
\text { - Prototyped, the performance was } \\
\text { not evaluated }\end{array}$ \\
\hline
\end{tabular}

\begin{tabular}{|c|c|c|c|}
\hline $\begin{array}{l}\text { Intelligent } \\
\text { Guidance Stick } \\
\text { [14] }\end{array}$ & $\begin{array}{l}\text { Ultrasonic } \\
\text { Sensors }\end{array}$ & $\begin{array}{l}\text { Outdoor } \\
\text { obstacle } \\
\text { and } \\
\text { potholes }\end{array}$ & $\begin{array}{l}\text { - Focused on obstacles and potholes } \\
\text { detection } \\
\text { - No testing result was presented for } \\
\text { pothole detection } \\
\text { - Stopped at conceptual research } \\
\text { stage }\end{array}$ \\
\hline $\begin{array}{l}\text { Ascending } \\
\text { Stairs } \\
\text { Detection } \\
\text { Device [15] }\end{array}$ & $\begin{array}{l}\text { Stereo } \\
\text { Camera Rig } \\
\text { Inertia } \\
\text { Measurement } \\
\text { Unit }\end{array}$ & $\begin{array}{l}\text { Indoor and } \\
\text { Outdoor } \\
\text { stairs }\end{array}$ & $\begin{array}{l}\text { - An ascending stairs detection } \\
\text { algorithm } \\
\text { - Encountered false detection in an } \\
\text { outdoor environment like pedestrian } \\
\text { crosswalks or shadow regions } \\
\text { - Stopped at conceptual research } \\
\text { stage }\end{array}$ \\
\hline $\begin{array}{l}\text { Assistive } \\
\text { System for } \\
\text { Existing } \\
\text { Rollator [16] }\end{array}$ & $\begin{array}{l}\text { Bumblebee2 } \\
\text { Stereo } \\
\text { Camera }\end{array}$ & $\begin{array}{l}\text { Indoor } \\
\text { descending } \\
\text { stairs }\end{array}$ & $\begin{array}{l}\text { - Only could detect descending stairs } \\
\text { Stopped at conceptual research } \\
\text { stage }\end{array}$ \\
\hline $\begin{array}{l}\text { Blind Man Stick } \\
\text { [17] }\end{array}$ & $\begin{array}{l}\text { Ultrasonic } \\
\text { Sensors } \\
\text { Accelerometer }\end{array}$ & $\begin{array}{l}\text { Indoor and } \\
\text { outdoor } \\
\text { white cane }\end{array}$ & $\begin{array}{l}\text { - } \begin{array}{l}\text { Experimental results were not } \\
\text { presented }\end{array} \\
\text { - } \begin{array}{l}\text { Prototyped, the performance was } \\
\text { not evaluated } \\
\text { - Stopped at conceptual research } \\
\text { stage }\end{array} \\
\end{array}$ \\
\hline $\begin{array}{l}\text { Wearable } \\
\text { Navigation } \\
\text { Assistant [18] }\end{array}$ & RGB-D Camera & $\begin{array}{l}\text { Indoor } \\
\text { staircase }\end{array}$ & $\begin{array}{l}\text { - A staircase detection algorithm } \\
\text { - Not tested in real world scenarios } \\
\text { and real time. } \\
\text { - Stopped at conceptual research } \\
\text { stage }\end{array}$ \\
\hline $\begin{array}{l}\text { Simple Jacket } \\
\text { Mobility Aid } \\
\text { [19] }\end{array}$ & $\begin{array}{l}\text { Ultrasonic } \\
\text { Sensors }\end{array}$ & $\begin{array}{l}\text { Indoor, } \\
\text { Outdoor }\end{array}$ & $\begin{array}{l}\text { - The sensors pointing position will } \\
\text { vary for different users, it requires } \\
\text { different configurations for different } \\
\text { users } \\
\text { - Stopped at conceptual research } \\
\text { stage }\end{array}$ \\
\hline $\begin{array}{l}\text { Ground Plane } \\
\text { Detection } \\
\text { Algorithm [20] }\end{array}$ & $\begin{array}{l}\text { Stereo } \\
\text { Camera Rig }\end{array}$ & Outdoor & $\begin{array}{l}\text { - Performance affected dropped when } \\
\text { the users face uphill, downhill or } \\
\text { camera alignment with horizontal } \\
\text { axis } \\
\text { - Stopped at conceptual research } \\
\text { stage }\end{array}$ \\
\hline $\begin{array}{l}\text { Surface } \\
\text { Condition } \\
\text { Detection } \\
\text { Method [21] }\end{array}$ & $\begin{array}{l}\text { Ultrasonic } \\
\text { Sensors }\end{array}$ & Outdoor & $\begin{array}{l}\text { - Method was not proven working on } \\
\text { an actual assistive device } \\
\text { - Data was collected based on the } \\
\text { ultrasonic sensor at the incident } \\
\text { angle of } 90^{\circ} \text { only but not tested with } \\
\text { different pointing angles } \\
\text { - Stopped at conceptual research } \\
\text { stage }\end{array}$ \\
\hline $\begin{array}{l}\text { Vision-Based } \\
\text { Device [22] }\end{array}$ & $\begin{array}{l}\text { GoPro HERO } 4 \\
\text { Silver Camera }\end{array}$ & Outdoor & $\begin{array}{l}\text { - A pothole and uneven surface } \\
\text { detection algorithm } \\
\text { - Limited for night time due to the low } \\
\text { laser beam visibility } \\
\text { - Stopped at conceptual research } \\
\text { stage }\end{array}$ \\
\hline
\end{tabular}

In this paper, a sensor-based ground plane checking system was proposed and developed with a LiDAR module. The design and development process are discussed in the next section. This research aims to prove that the developed solution can detect and recognise the ground plane conditions in front of the user. The design and performance of outdoor test scenarios are also documented in the following sections.

\section{System Concept and Design}

The design of the proposed system addressed the issues the existing works concluded [11]. First, the selection of range sensors is better for ground plane checking in terms of the cost, efficiency and invasiveness as compared with vision sensors. Second, the range sensors model can offer a better detection range when used together with the traditional white cane. The model also focuses on ground plane checking as a supplementary support aid to the traditional white cane to enhance visually impaired mobility. 
The proposed LiDAR based model consists of a micro LiDAR module, a micro servo motor, a Bluetooth module and an Arduino Pro Mini as the processing unit for the system (Figure 1). The LiDAR based model has three operations: distance sensing with changing pointing direction, ground plane recognition and audible feedback generation. At the start of its operation, the model connects to the mobile phone app through Bluetooth connection. The audible feedback provides information to the user for any changes in the model, including the status and detection results (Figure 2).

During its operation, the ground plane checking system tracks the changes in distance constantly in front of the user. The detection process starts by taking reference distance values at two different angles, $30^{\circ}$ and $50^{\circ}$ from the horizontal axis. The switching of the pointing position is achieved by the servo motor. Once there is any frontal changes occur within the operation, the system collects the distance data at different pointing positions for analysis and recognition of the frontal ground plane conditions according to the algorithm described in [12] [13]. The full detection process can be observed in the ground plane detection block diagram (Figure 3 ).

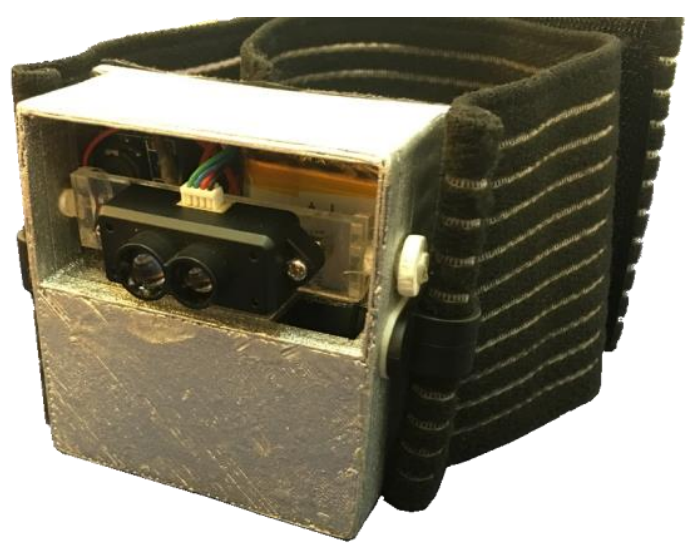

Figure 1. LiDAR Based Model.

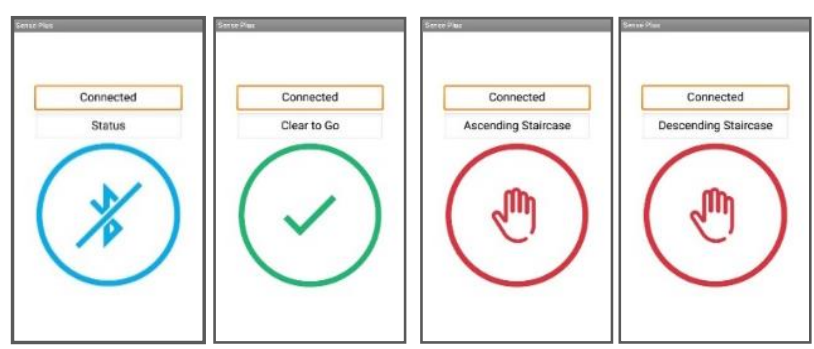

Figure 2. Mobile App Screens.

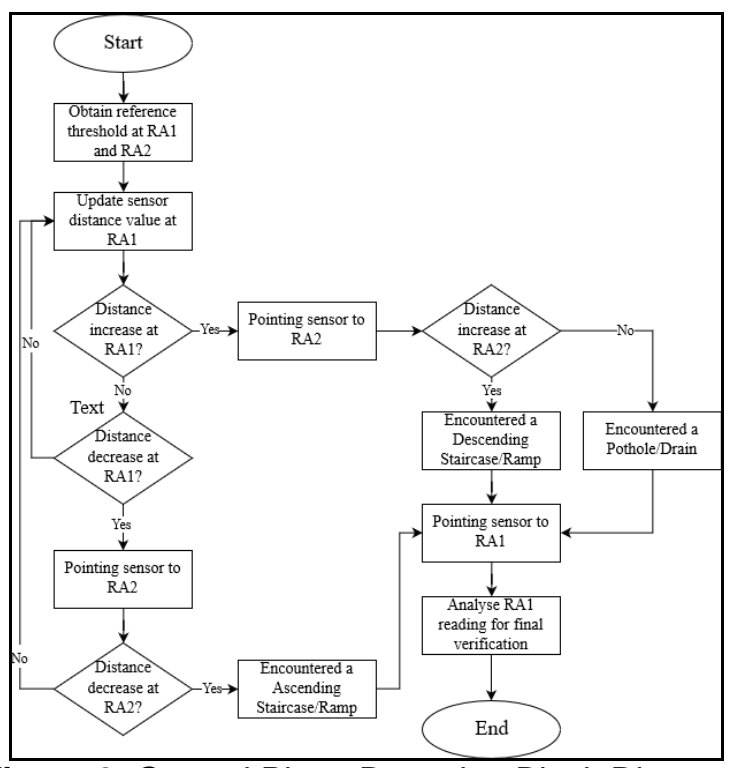

Figure 3. Ground Plane Detection Block Diagram.

\section{Ascending Staircases and Ramps Detection}

For the detection between the ascending staircase and ramp, one sensor device positioned on the user above the knee level will be used. Figure 4 and 5 show the modelling diagram used for the ascending staircase and ascending ramp.

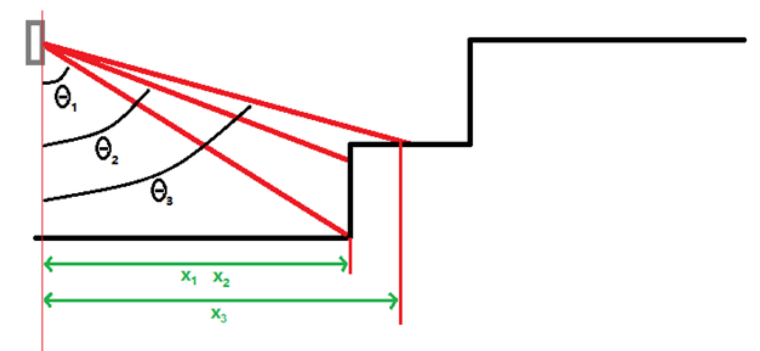

Figure 4. Ascending Staircase Modelling Diagram.

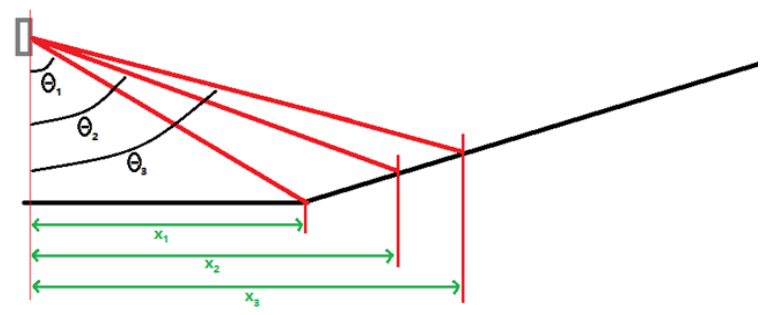

Figure 5. Ascending Ramp Modelling Diagram.

During the detection process, the sensor will be measuring the distance to the ground at reference point one, $\theta_{1}$ to ensure a safe ground plane condition with a constant distance, $x_{1}$. When there is a decrease in the distance at $\theta_{1}$, the sensor will be rotated towards the second reference point, $\theta_{2}$ to identify the changes in distance from the sensor. The distance, $x_{2}$ is calculated by using the $\theta_{2}$. 


$$
x_{2}=\text { Measured Distance } * \sin \theta_{2}
$$

The verification between the ascending staircase and ramp will be identified based on the range reading obtained from both position one and position two.

$$
\begin{aligned}
& \text { If }\left(x_{R 1}-x_{1}<50\right), \quad \text { rampFlag }=1 ; \\
& \text { If }\left(x_{R 2}-x_{2}>200 \text { \&\& rampFlag }==1\right), \quad \text { upRampScenario = true; } \\
& \text { If }\left(x_{R 2}-x_{2}>100 \text { \&\& rampFlag }==0\right), \quad \text { upStaircaseScenario }=\text { true; }
\end{aligned}
$$

The verification between ascending staircase and ramp starts from checking changes of the range reading at position one and then followed by the changes at position two. If the range reading at position one fulfils the condition of a ramp scenario, then the ramp flag will be marked. If the condition at the second position is fulfilled, then it will be identified as an ascending ramp. On the other hand, if the ramp flag is not marked and the second condition at the second position is fulfilled, then it will be identified as an ascending staircase.

\section{Descending Staircase and Ramps Detection}

Similarly, for the detection of the descending staircase and ramp, two sensor devices on both sides will be used. The first sensor will be used to ensure a safe ground plane condition with a constant distance, $x_{1}$ by measuring the distance at $\theta_{1}$. Figure 6 and 7 show the modelling diagram used for the descending staircase and descending ramp.

During the detection process, the sensor measures the distance to the ground at $\theta_{2}$ for a further distance. When the sensor detected an increase in the distance at $\theta_{2}$, the distance, $x_{2}$ is calculated. If the calculated distance, $x_{2}$ increased by a very huge amount from the reference distance value, $x_{1}$, then it will be identified as either a descending staircase or a descending ramp.

If $\left(x_{R 1}-x_{1}<150\right), \quad$ rampFlag $=1$;

If $\left(x_{R 2}-x_{2}<800\right.$ \&\& rampFlag $\left.==1\right), \quad$ downRampScenario = true;

If $\left(x_{R 2}-x_{2}>x_{R 2}-100\right.$ \&\& rampFlag $\left.==0\right), \quad$ downStaircaseScenario $=$ true;

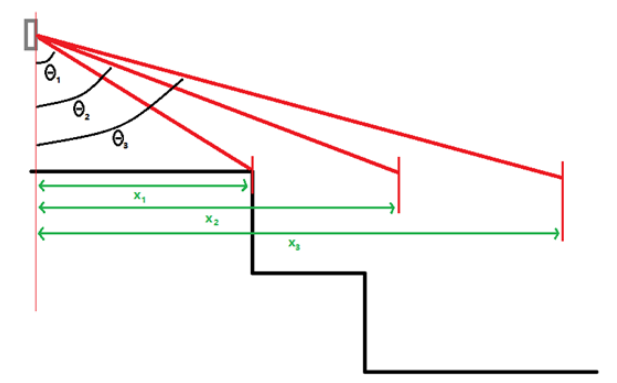

Figure 6. Descending Staircase Modelling Diagram.

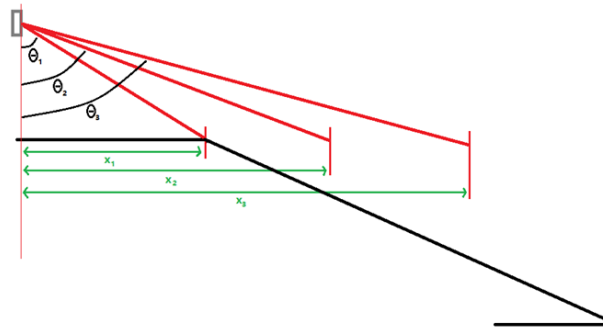

Figure 7. Descending Ramp Modelling Diagram.

\section{Drains and Potholes Detection}

The detection process for drain and potholes is the same as the detection for descending staircase and ramp. Figure 8 shows the modelling diagram used for drains and potholes.

When there is an increase in the distance at $\theta_{1}$, the sensor is rotated to the second reference point, $\theta_{2}$. The current reading is used for verifying the condition between the descending staircase, ramp, drains, and pothole.

$$
\text { If }\left(x_{2}>x_{R 2}-50 \& \& x_{2}<x_{R 2}+50\right), \quad \text { drainPotholescenario = true; }
$$

When the condition for drains and pothole was fulfilled, the sensor will be rotated back to the first reference point, $\theta_{1}$ to obtain the reading for the verification between drains and pothole.

$$
\begin{aligned}
& \text { If }\left(x_{1}-x_{R 1}>200 \text { \&\& drainPotholeScenario }==1\right), \quad \text { drainScenario }=\text { true; } \\
& \text { If }\left(x_{1}-x_{R 1}<200 \& \& \text { drainPotholeScenario }==0\right), \quad \text { potholescenario }=\text { true; }
\end{aligned}
$$

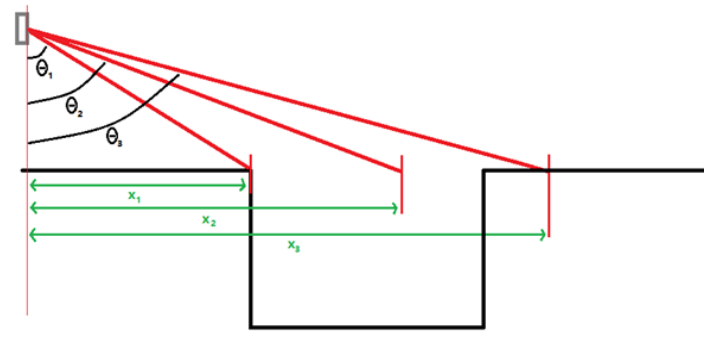

Figure 8. Pothole and Drains Modelling Diagram.

\section{Performance Evaluation}

The successful development and functional testing of the proposed ground plane checking system [12] greenlighted further extensive testing of its performance in the outdoor environment. This section documented the selected scenarios that simulate the daily navigation route to examine the outdoor performance of the proposed model. The selected path-based scenarios are made up of 
different combinations of ground plane conditions which include staircases, ramps, drains, potholes and steps.

Figure 9 demonstrated the testing conditions for the path-based scenarios. The testing was conducted under normal daylight conditions, with the subject wearing the proposed model and blindfolded. Figure 10 to Figure 19 shows the ten testing scenarios used to test the outdoor ground plane checking performance of the proposed model. The testing followed the route arrows in the figures and each path testing was conducted three times to obtain an average performance of the system.

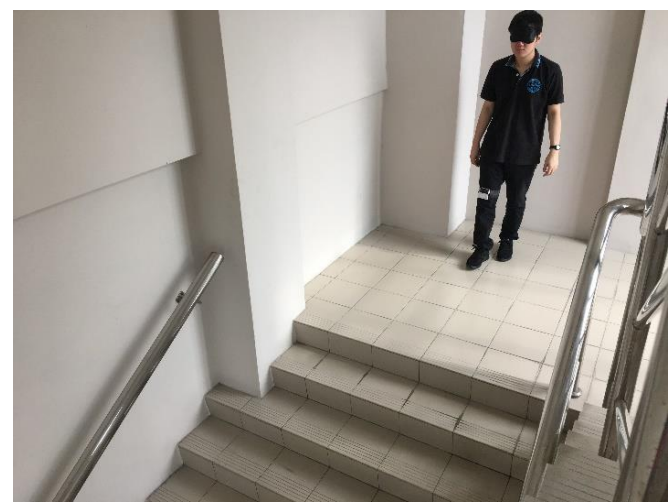

Figure 9. Testing subject with the model and blindfolded.

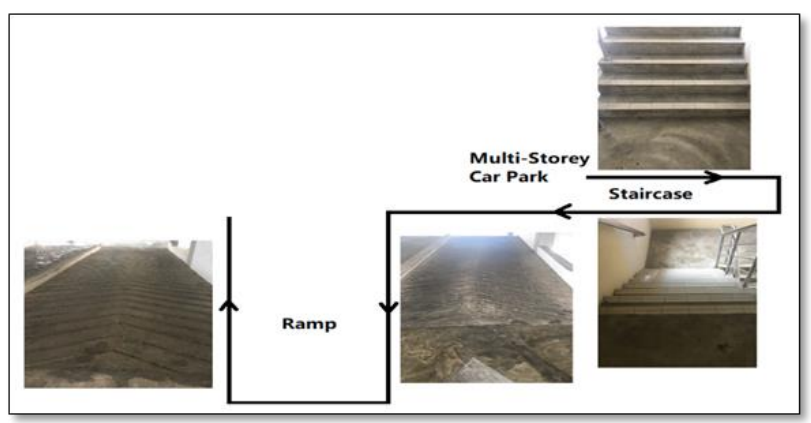

Figure 10. Testing Path 1.

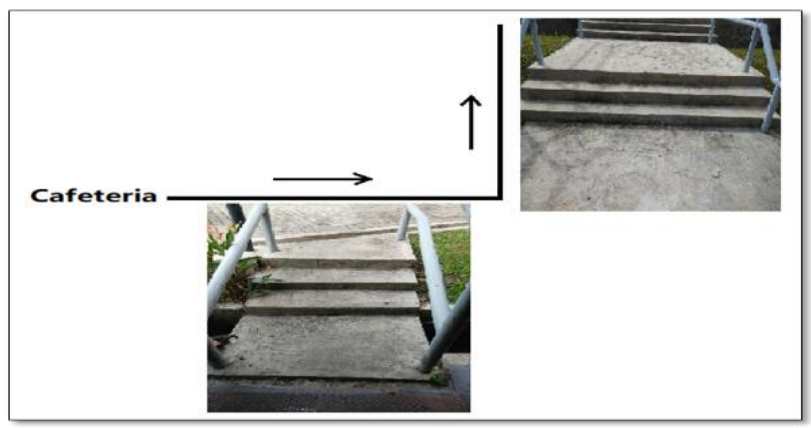

Figure 11. Testing Path 2.

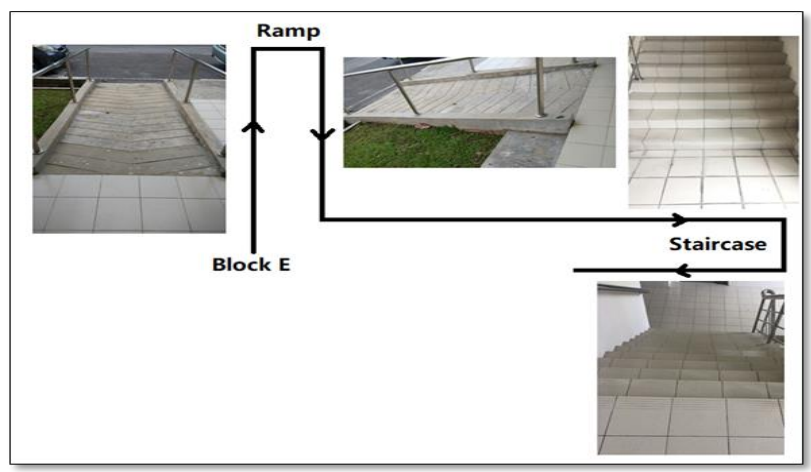

Figure 12. Testing Path 3.

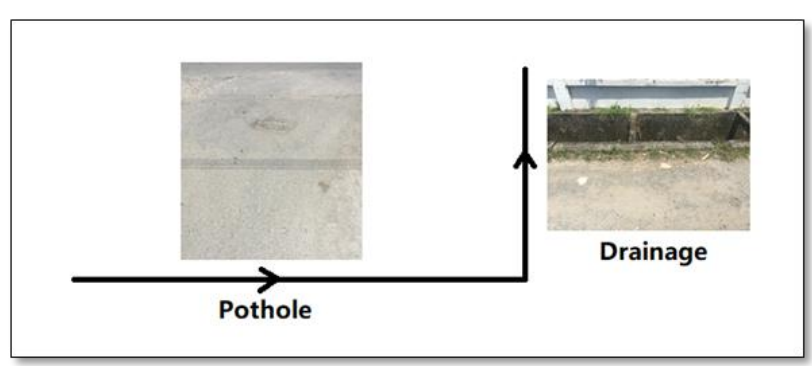

Figure 13. Testing Path 4.

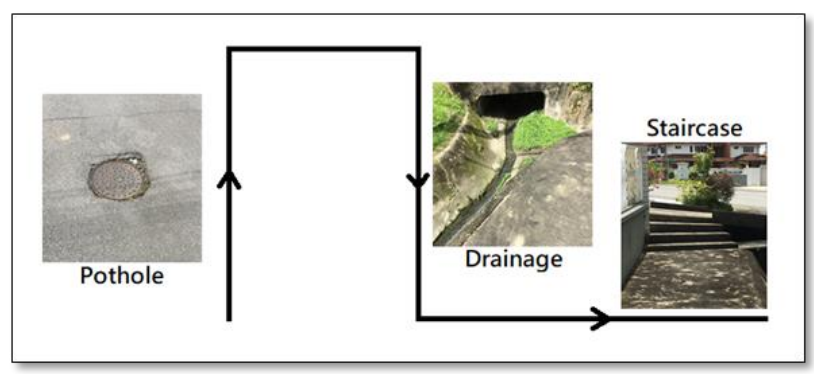

Figure 14. Testing Path 5.

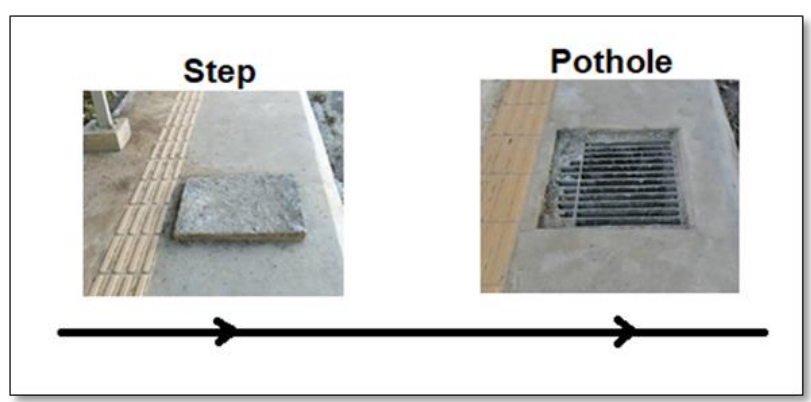

Figure 15. Testing Path 6.

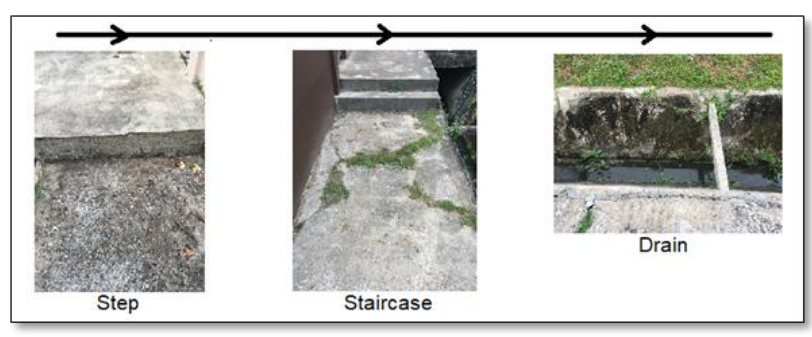

Figure 16. Testing Path 7. 


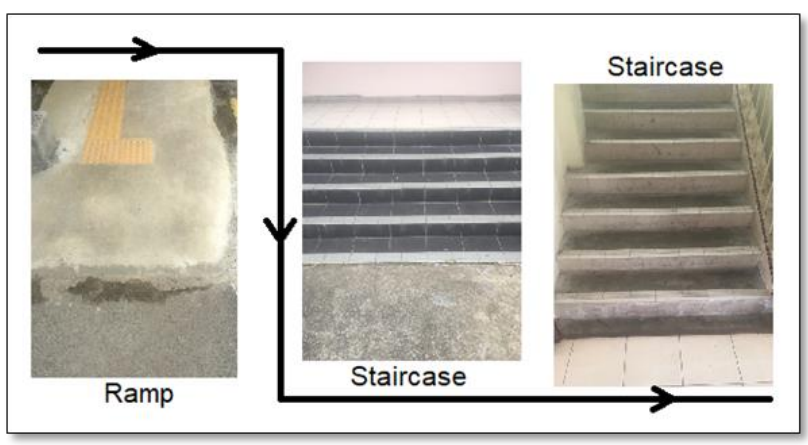

Figure 17. Testing Path 8.

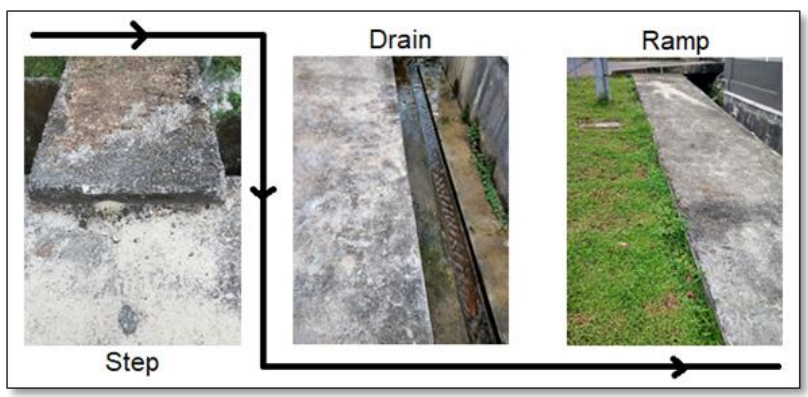

Figure 18. Testing Path 9.

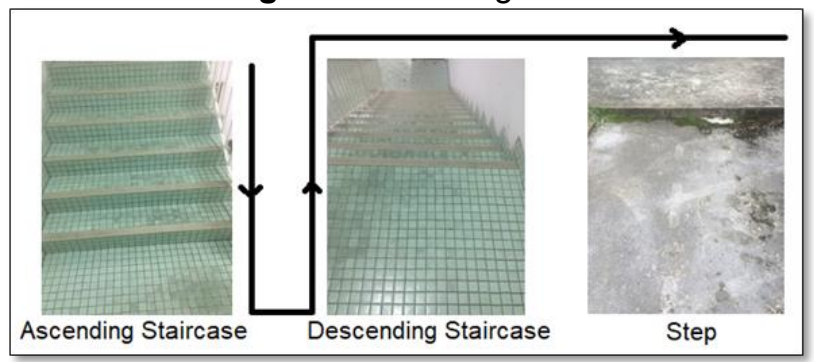

Figure 19. Testing Path 10.

\section{Findings and Discussion}

The testing data collected from the ten path-based scenarios were evaluated based on three terms, the success recognition rate, the false positive and negative rate. Table 2 and Table 3 tabulated the testing results for the ten path-based scenarios with the number of success detection, false detection, total detection, false positive detection, false negative detection and the three evaluation terms.

The rate of success recognition shows the accuracy of the frontal hazards detection and recognition. Besides, it is understood that the false positive rate is a false alarm, at which the detection suggests the presence of the frontal hazards, but it does not. The false negative rate is the opposite of the false positive rate, where the detection implies the absence of the frontal hazards, but in fact it does. The equation for the three terms described above is available in [12].
Table 2. Conclusive Results for Testing Path 1 to 5.

\begin{tabular}{|c|c|c|c|c|c|}
\hline Testing Path & 1 & 2 & 3 & 4 & 5 \\
\hline Experiment 1 & & & & & \\
\hline No. of Success Detection & 88 & 46 & 102 & 46 & 59 \\
\hline No. of False Detection & 5 & 2 & 8 & 4 & 4 \\
\hline Total No. of Detection & 93 & 48 & 110 & 50 & 63 \\
\hline Success Rate & $94.62 \%$ & $95.83 \%$ & $92.73 \%$ & $92.00 \%$ & $93.65 \%$ \\
\hline No. of FP Detection & 1 & 0 & 3 & 2 & 2 \\
\hline No. of FN Detection & 4 & 2 & 5 & 2 & 2 \\
\hline False Positive Rate & $1.08 \%$ & $0 \%$ & $2.73 \%$ & $4 \%$ & $3.17 \%$ \\
\hline False Negative Rate & $4.30 \%$ & $4.17 \%$ & $4.55 \%$ & $4 \%$ & $3.17 \%$ \\
\hline Experiment 2 & & & & & \\
\hline No. of Success Detection & 84 & 45 & 89 & 46 & 65 \\
\hline No. of False Detection & 4 & 1 & 10 & 5 & 3 \\
\hline Total No. of Detection & 88 & 46 & 99 & 51 & 68 \\
\hline Success Rate & $95.45 \%$ & $97.83 \%$ & $89.90 \%$ & $90.20 \%$ & $95.59 \%$ \\
\hline No. of FP Detection & 0 & 1 & 4 & 2 & 1 \\
\hline No. of FN Detection & 4 & 0 & 6 & 3 & 2 \\
\hline False Positive Rate & $0 \%$ & $2.17 \%$ & $4.04 \%$ & $3.92 \%$ & $1.47 \%$ \\
\hline False Negative Rate & $4.55 \%$ & $0 \%$ & $6.06 \%$ & $5.88 \%$ & $2.94 \%$ \\
\hline Experiment 3 & & & & & \\
\hline No. of Success Detection & 89 & 44 & 88 & 49 & 56 \\
\hline No. of False Detection & 3 & 3 & 10 & 3 & 5 \\
\hline Total No. of Detection & 92 & 47 & 98 & 52 & 61 \\
\hline Success Rate & $96.74 \%$ & $93.62 \%$ & $89.80 \%$ & $94.23 \%$ & $91.80 \%$ \\
\hline No. of FP Detection & 0 & 1 & 3 & 2 & 2 \\
\hline No. of FN Detection & 3 & 2 & 7 & 1 & 3 \\
\hline False Positive Rate & $0 \%$ & $2.13 \%$ & $3.06 \%$ & $3.85 \%$ & $3.28 \%$ \\
\hline False Negative Rate & $3.26 \%$ & $4.26 \%$ & $7.14 \%$ & $1.92 \%$ & $4.92 \%$ \\
\hline Average Success Rate & $95.60 \%$ & $95.76 \%$ & $90.84 \%$ & $92.14 \%$ & $93.68 \%$ \\
\hline $\begin{array}{c}\text { Standard Deviation of } \\
\text { Success Rate }\end{array}$ & $0.87 \%$ & $1.72 \%$ & $1.33 \%$ & $1.65 \%$ & $1.55 \%$ \\
\hline Average False Positive Rate & $1.08 \%$ & $1.43 \%$ & $3.28 \%$ & $3.92 \%$ & $2.64 \%$ \\
\hline Average False Negative Rate & $4.04 \%$ & $2.81 \%$ & $5.92 \%$ & $3.93 \%$ & $3.68 \%$ \\
\hline $\begin{array}{c}\text { Standard Deviation of False } \\
\text { Positive Rate }\end{array}$ & $0.51 \%$ & $1.01 \%$ & $0.56 \%$ & $0.06 \%$ & $0.83 \%$ \\
\hline $\begin{array}{c}\text { Standard Deviation of False } \\
\text { Negative Rate }\end{array}$ & $0.56 \%$ & $1.99 \%$ & $1.06 \%$ & $1.62 \%$ & $0.88 \%$ \\
\hline
\end{tabular}

Table 3. Conclusive Results for Testing Path 6 to 10

\begin{tabular}{|c|c|c|c|c|c|}
\hline Testing Path & 6 & 7 & 8 & 9 & 10 \\
\hline Experiment 1 & & & & & \\
\hline No. of Success Detection & 34 & 72 & 78 & 75 & 84 \\
\hline No. of False Detection & 3 & 6 & 7 & 4 & 6 \\
\hline Total No. of Detection & 37 & 78 & 85 & 79 & 90 \\
\hline Success Rate & $91.89 \%$ & $92.31 \%$ & $91.76 \%$ & $94.94 \%$ & $93.33 \%$ \\
\hline No. of FP Detection & 1 & 3 & 2 & 2 & 2 \\
\hline No. of FN Detection & 2 & 3 & 5 & 2 & 4 \\
\hline False Positive Rate & $2.70 \%$ & $3.85 \%$ & $2.35 \%$ & $2.53 \%$ & $2.22 \%$ \\
\hline False Negative Rate & $5.41 \%$ & $3.85 \%$ & $5.88 \%$ & $2.53 \%$ & $4.44 \%$ \\
\hline Experiment 2 & & & & & \\
\hline No. of Success Detection & 38 & 66 & 74 & 82 & 75 \\
\hline No. of False Detection & 3 & 7 & 5 & 9 & 5 \\
\hline Total No. of Detection & 41 & 73 & 79 & 91 & 80 \\
\hline Success Rate & $92.68 \%$ & $90.41 \%$ & $93.67 \%$ & $90.11 \%$ & $93.75 \%$ \\
\hline No. of FP Detection & 0 & 3 & 2 & 3 & 1 \\
\hline No. of FN Detection & 3 & 4 & 3 & 6 & 4 \\
\hline False Positive Rate & $0 \%$ & $4.11 \%$ & $2.53 \%$ & $3.30 \%$ & $1.25 \%$ \\
\hline False Negative Rate & $7.32 \%$ & $5.48 \%$ & $3.80 \%$ & $6.59 \%$ & $5.00 \%$ \\
\hline Experiment 3 & & & & & \\
\hline No. of Success Detection & 37 & 67 & 75 & 78 & 79 \\
\hline No. of False Detection & 2 & 5 & 6 & 6 & 8 \\
\hline Total No. of Detection & 39 & 72 & 81 & 84 & 87 \\
\hline Success Rate & $94.87 \%$ & $93.06 \%$ & $92.59 \%$ & $92.86 \%$ & $90.80 \%$ \\
\hline No. of FP Detection & 2 & 2 & 3 & 4 & 3 \\
\hline No. of FN Detection & 0 & 3 & 3 & 2 & 5 \\
\hline False Positive Rate & $5.13 \%$ & $2.78 \%$ & $3.70 \%$ & $4.76 \%$ & $3.45 \%$ \\
\hline False Negative Rate & $0 \%$ & $4.17 \%$ & $3.70 \%$ & $2.38 \%$ & $5.75 \%$ \\
\hline Average Success Rate & $93.15 \%$ & $91.92 \%$ & $92.68 \%$ & $92.63 \%$ & $92.63 \%$ \\
\hline $\begin{array}{c}\text { Standard Deviation of } \\
\text { Success Rate }\end{array}$ & $1.26 \%$ & $1.12 \%$ & $0.78 \%$ & $1.98 \%$ & $1.30 \%$ \\
\hline Average False Positive Rate & $2.61 \%$ & $3.58 \%$ & $2.86 \%$ & $3.53 \%$ & $2.31 \%$ \\
\hline Average False Negative Rate & $4.24 \%$ & $4.50 \%$ & $4.46 \%$ & $3.84 \%$ & $5.06 \%$ \\
\hline $\begin{array}{c}\text { Standard Deviation of False } \\
\text { Positive Rate }\end{array}$ & $2.10 \%$ & $0.58 \%$ & $0.60 \%$ & $0.92 \%$ & $0.90 \%$ \\
\hline $\begin{array}{c}\text { Standard Deviation of False } \\
\text { Negative Rate }\end{array}$ & $3.10 \%$ & $0.71 \%$ & $1.00 \%$ & $1.95 \%$ & $0.54 \%$ \\
\hline
\end{tabular}

Path 1, 2, 3, 8 and 10 of the test consists of the combination of staircases, ramps and steps within the route. Among these five path tests, the proposed model managed to achieve an average success rate of above $90 \%$ with an average false positive and negative rate of less than $6 \%$. Within these three paths, scenario 3 was 
observed with the lowest success detection rate and the highest false negative rate. The cause of the high false negative in testing path 3 was that the ramp has a very small slope, hence it created uncertainty for the ramp to be observed. The proposed model managed to maintain consistent detection and recognition with an average success rate of above $90 \%$ while minimizing the false negative rate.

Path 4, 5, 6, 7 and 9 poses similar navigation challenges with the combination involving potholes and drains. The proposed model obtained an average success rate of above $91 \%$ with average false positive false positive and negative rate of below $5 \%$ along these test routes. Comparing the results of the ten test paths with various ground plane combinations, an overall success rate of $93.10 \%$ is obtained, with an overall false positive rate of $2.72 \%$ and an average false negative rate of $4.25 \%$. Overall, the path-based tests revealed the potential of the proposed model to provide effective frontal ground plane checking for the user. As a wearable assistive technology, the proposed model provides essential features by achieving a low-cost, lightweight and simple to use.

\section{Conclusion and Future Work}

To conclude, the proposed model presented an effective frontal ground plane checking approach by examining the frontal changes with the LIDAR module. The model was evaluated using experiments based on the outdoor paths with various combinations of ground plane conditions. Overall, the results showed that the model possesses the ability to support people with visual impairment in outdoor navigation to reduce the chances of accidents and enhance their mobility.

The next possible step is to extend the functionalities of the proposed model to support the visually impaired while tackling other challenges such as obstacle detection and avoidance. Besides, the current model uses only one sensor for 2D data detection and thus is limited in the detection of some ground plane conditions, which are loose gravel surfaces and natural debris. The system can also be strengthened with additional sensors to tackle ground plane conditions that cannot be detected by using the LiDAR module alone. Last but not least, additional scenarios should be applied to the experiments to help improve the approach to greater precision.

\section{Acknowledgements.}

This work is supported by the Swinburne Melbourne-Sarawak Research Collaboration Scheme 2017-2019.

\section{References}

[1] Ahmed, T., Hoyle, R., Shaffer, P., Connelly, K., Crandall, D., Kapadia, A. Understanding the Physical Safety, Security, and Privacy Concerns of People with Visual Impairments. IEEE Internet Computing. 2017; 21(3): pp.56-63.
[2] Deverell, L, Meyer, D, Lau, BT, Abdullah Al, M, Sukunesan, S, Bhowmik, J, Chai, A, McCarthy, C, Pan, Z, Pipingas, A, Fakir, MAI. Optimising technology to measure functional vision, mobility and service outcomes for people with low vision or blindness: protocol for a prospective cohort study in Australia and Malaysia. BMJ Open, 2017; 7(12).

[3] Legood, R, Scuffham, P \& Cryer, C. Are we blind to injuries in the visually impaired? A review of the literature. Injury Prevention, 2002; 8(2): p. 155.

[4] Perez-Yus, A, Gutierrez-Gomez, D, Lopez-Nicolas, G, Guerrero, JJ. Stairs detection with odometry-aided traversal from a wearable RGB-D camera. Computer Vision and Image Understanding, 2017; 154(1): pp. 192205.

[5] Cloix, S, Bologna, G, Weiss, V, Pun, T, Hasler, D. Descending Stairs Detection with Low-Power Sensors, in L Agapito, MM Bronstein and C Rother (eds), Computer Vision - ECCV 2014 Workshops: Zurich, Switzerland, September 6-7 and 12, 2014, Proceedings, Part III, Springer International Publishing, Cham, 2015; pp. 658672.

[6] Stacey, A. Wheelchair-bound and blind teen dies after falling down stairs at Lozells school. Birminghan Mail, 14 September 2016.

[7] Rojin. Blind man's death on Iran bridge a wake-up call for authorities. The Observers - France 24, 2017.

[8] Zilber, A. Hero bystanders leap onto train tracks to help a visually impaired man who fell and broke his leg - a minute before oncoming train arrives in Atlanta. Associated Press \& Dailymail.com, 2017; $<$ http://www.dailymail.co.uk/news/article-

4388000/Bystanders-risk-lives-help-visually-impairedman-tracks.html>.

[9] Aoki, M. Blind man's death at subway station reignites call for safety barriers. The Japan Times LTD, 2016; <http://www.japantimes.co.jp/news/2016/08/18/national/bl ind-mans-death-subway-station-reignites-call-safetybarriers/>.

[10] Dawn, Chan. Klang Council facing legal action from family of boy who fell into manhole. New Straits Times, 2016;

<https://www.nst.com.my/news/2016/02/128764/klangcouncil-facing-legal-action-family-boy-who-fellmanhole>.

[11] Bouhamed, SA, Kallel, IK, Masmoudi, DS. New electronic white cane for stair case detection and recognition using ultrasonic sensor. International Journal of Advanced Computer Science \& Applications. 2013; 4(6).

[12] Ishiwata, K, Sekiguchi, M, Fuchida, M, Nakamura, A. Basic study on step detection system for the visually impaired. IEEE International Conference on Mechatronics and Automation. 2018; 1332-1337.

[13] Sheth, R, Rajandekar, S, Laddha, S, Chaudhari, R. Smart White Cane-An Elegant and Economic Walking Aid. AJER, e-ISSN. 2014; 3(10): 84-89.

[14] Saraf, M, Shehzad, M, Jadhav, N. An IVR Based Intelligent Guidance Stick for Blind. International Journal of Current Engineering and Technology. 2014; 4(3).

[15] Harms, H., Rehder, E., Schwarze, T., Lauer, M. Detection of ascending stairs using stereo vision. IEEE/RSJ International Conference on Intelligent Robots and Systems (IROS). 2015; Washington, DC: IEEE.

[16] Cloix, S., Bologna, G., Weiss, V., Pun, T., Hasler, D. Descending stairs detection with low-power sensors. 
Computer Vision - ECCV 2014 Workshops. 2014; 658672, New York, NY: Springer.

[17] Parikh, A., Shah, D., Popat, K., Narula, H. Blind man stick using programmable interrupt controller (PIC). Procedia Computer Science. 2015; 45: 558-563.

[18] Pérez-Yus, A., López-Nicolás, G., Guerrero, J. Detection and modelling of staircases using a wearable depth sensor. Computer Vision - ECCV 2014 Workshops. 2015; 449463, New York, NY: Springer.

[19] Sourab, B., Ranganatha Chakravarthy, H. S., D’Souza, S. Design and implementation of mobility aid for blind people. International Conference on Power and Advanced Control Engineering (ICPACE). 2015; Washington, DC: IEEE.

[20] Herghelegiu, P., Burlacu, A., Caraiman, S. Robust ground plane detection and tracking in stereo sequences using camera orientation. 20th International Conference on System Theory, Control and Computing (ICSTCC). 2016; Washington, DC: IEEE.

[21] Nakashima, S., Aramaki, S., Kitazono, Y., Mu, S., Tanaka, K., Serikawa, S. Road surface condition distinction method using reflection intensities obtained by ultrasonic sensor. International Symposium on Computer, Consumer and Control (IS3C). 2016; Washington, DC: IEEE.

[22] Rao, A., Gubbi, J., Palaniswami, M., Wong, E. A visionbased system to detect potholes and uneven surfaces for assisting blind people. IEEE International Conference on Communications (ICC). 2016; Washington, DC: IEEE.

[23] Chai, A.B.C., Lau, B.T., Chai, A., Deverell, L., Mahmoud, A., McCarthy, C. Technological Trends in Improved Mobility of the Visually Impaired. EAI/Springer Innovations in Communications and Computing; 2020. 4, Comprehensive Literature Reviews on Ground Plane Checking for the Visually Impaired; p. 85-104.

[24] Chai, A.B.C., Lau, B.T., Chai, A., Deverell, L., Mahmoud, A., and McCarthy, C., 2018, 'An Autonomous LiDAR Based Ground Plane Hazards Detector for the Visually Impaired', 2018 IEEE EMBS Conference on Biomedical Engineering and Sciences (IECBES), Dec. 2018. [Indexed by SCOPUS]. Doi: 10.1109/IECBES.2018.8626675.

[25] Chai, A.B.C., Lau, B.T., Chai, A., and Mahmoud, A., 2019, 'Wearable Ground Plane Hazards Detection and Recognition System for the Visually Impaired ', 2019 The 3rd International Conference on E-Society, E-Education and E-Technology (ICSET), Aug. 2019.

[26] Chai, A.B.C., Lau, B.T., Meyer, D., Chai, A., Pan, Z., Deverell, L., Mahmoud, A., and McCarthy, C., 2018. A ground plane hazards detection tool for the visually impaired. International Journal of Mechanical Engineering and Robotics Research, ISSN: 2278-0149. 